WARSZTATY Z GEOGRAFII TURYZMU

ISBN 978-83-7969-262-0 $\quad$ s. 161-178

http://dx.doi.org/10.18778/7969-262-0.11

Dorota SZCZUKA

Urząd Miasta w Kazimierzu Dolnym

Bogdan WŁODARCZYK

Uniwersytet Łódzki

\title{
TURYSTYKA I KULTURA W KAZIMIERZU DOLNYM
}

Kazimierz Dolny to jedna ze współczesnych ikon polskiej kultury i turystyki, przykład "starego, dobrego małżeństwa”, w którym jedno nie istnieje bez drugiego, nie rozwija się i nie odczuwa pełni szczęścia. Gdyby z jakichś powodów w stadle tym musiał nastąpić „rozwód”, turystyka Kazimierza Dolnego bez kultury umarłaby $w$ bardzo niedługim czasie, a kultura bez turystyki „,czułaby się” niechciana i osamotniona.

\section{Kazimierz Dolny - pomnik historii}

Na pewno tym, co wpłynęło na dzisiejszy charakter miasteczka, była bardzo długa, ciekawa historia miejsca, utożsamianego z królem Kazimierzem Wielkim i legendami z nim związanymi, w tym z najważniejszą: o miłości króla do pięknej żydowskiej oblubienicy Estery, wywodzącej się z miejscowej społeczności. Ogromną rolę odegrało także dziedzictwo kulturowe, jego wybitna średniowieczna i renesansowa architektura, harmonijnie wkomponowane w nadwiślański krajobraz poprzecinany lessowymi wąwozami.

Kazimierz Dolny to ponad 800 lat udokumentowanej historii. Pierwsze osadnictwo, potwierdzone w źródłach pisanych, pojawiło się tu w wieku XII. 
Miejsce było jednym z tych, gdzie swój zamek polecił budować król Kazimierz Wielki. Miasto nazywane było „małym Gdańskiem” z racji tego, że w wiekach XVI i XVII, w okresie największej prosperity, funkcjonował tu jeden z ważniejszych w Rzeczypospolitej portów przeładunkowych z ponad 60 pięknie zdobionymi spichlerzami zbożowymi nad brzegiem Wisły, z prężnie rozwijającym się handlem i liczbą mieszkańców dorównującą dzisiejszej. $\mathrm{Z}$ tego okresu pozostały najcenniejsze realizacje architektoniczne, takie jak kościół farny w jego renesansowej formie, manierystyczne kamienice braci Przybyłów, kamienice: Celejowska, Biała, kościół oo. Franciszkanów, kościół św. Anny i spichlerze zbożowe. Tworzyli tu m.in.: architekt królewski Santi Gucci Fiorentino oraz Jakub Balin - autor renesansowej przebudowy fary.

Genius loci i niepowtarzalny urok Kazimierza Dolnego wyrażają się nie tylko poprzez wybitną architekturę monumentalną, ale także harmonijnie zespolone $\mathrm{z}$ nią budownictwo drewniane, podcienia, gontowe dachy, małą architekturę $\mathrm{w}$ postaci studzien czy kapliczek. Całość dopełnia wybitny w skali kraju krajobraz: małe miasteczko z niską zabudową, z bielejącymi od słońca ścianami budynków $\mathrm{z}$ wapiennego kamienia, położone nad brzegiem Wisły, otoczone wysokimi zielonymi wzgórzami, poprzecinanymi głębokimi lessowymi wąwozami (fot. 1-2).

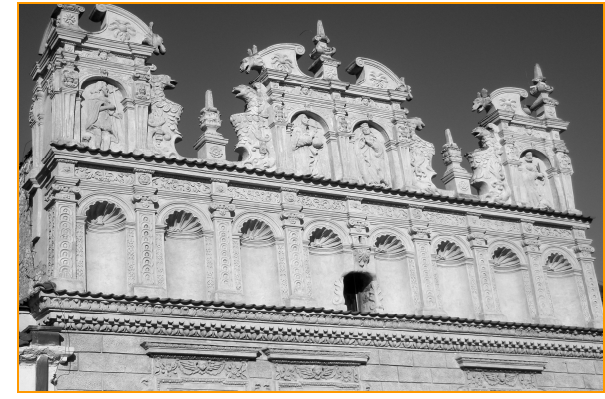

Fot. 1. Attyka Kamienicy Celejowskiej

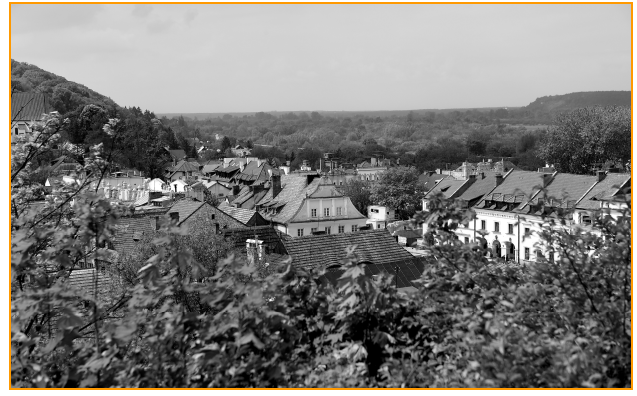

Fot. 2. Panorama miasta widziana z Góry Trzech Krzyży

Źródło: Urząd Miasta w Kazimierzu Dolnym

Wszystkie te walory zostały dostrzeżone już dawno (m.in. METZER-SOBOTKOWSKA 2006, NIEGODZISZ 2006, KOENNER 2008), a wyjątkowość zespołu „przypieczętowana” została decyzją Wojewódzkiego Konserwatora Zabytków o uznaniu za zabytek i wpisaniu do rejestru zabytków (decyzje z 1947, 1966 i 1983 r.). Jednak pierwsze próby uznania zabytkowego charakteru Ka- 
zimierza podjęto już w 1947 r., z którego pochodzi dokument określający miasto jako zabytek.

W myśl przywołanych aktów prawnych w Kazimierzu Dolnym ochronie konserwatorskiej podlega zespół urbanistyczno-architektoniczno-krajobrazowy miasta wraz ze wszystkimi placami, ulicami, drogami, budynkami murowanymi i drewnianymi, ruinami, wąwozami i drzewostanem (wszystkie te elementy wymienione są $\mathrm{w}$ sentencji decyzji o wpisaniu do rejestru). Dodatkowo niemal cały obszar gminy objęty jest ochroną krajobrazową (Kazimierski Park Krajobrazowy).

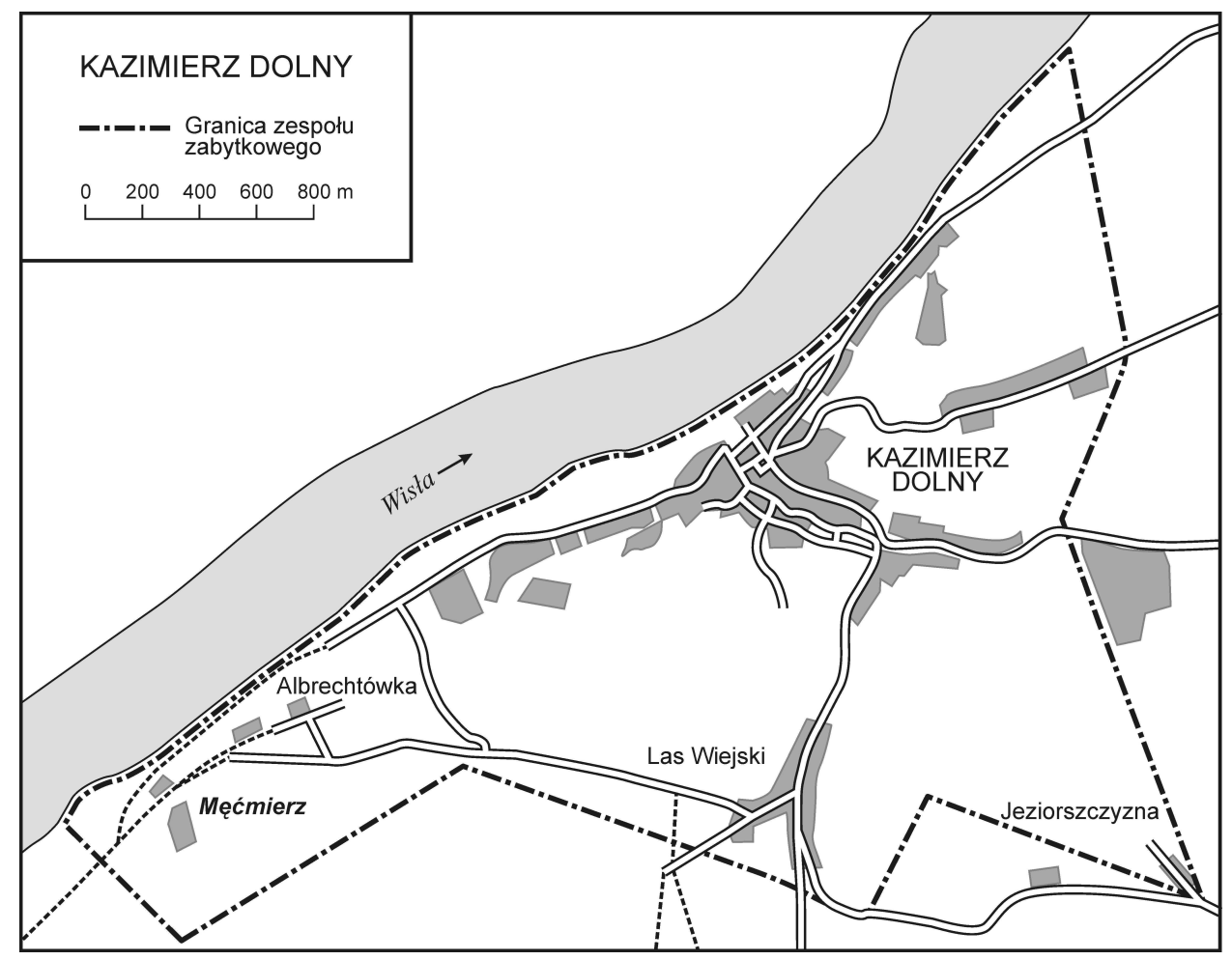

Rys. 1. Granice pomnika historii i zespołu zabytkowego w Kazimierzu Dolnym Źródło: www.nid.pl

Wszystkie wymienione inicjatywy sprawiły, że Kazimierz Dolny został uznany również za pomnik historii. Stało się to dzięki Zarządzeniu Prezydenta Rzeczypospolitej Polskiej z 8 września 1994 r. Miasto znalazło się w bardzo zaszczytnym gronie kilkunastu najcenniejszych „skarbnic” polskiej historii, ta- 
kich jak Biskupin, Grunwald, Kraków, Warszawa czy Malbork, które jako pierwsze, tego samego dnia zostały wpisane przez Prezydenta RPL Lecha Wałęsę na listę pomników historii. Wpis ten należy traktować jako ogromne wyróżnienie i nobilitację całego zespołu miejskiego, który uznano za jedno z najważniejszych miejsc $\mathrm{w}$ kraju, zabytek o szczególnym znaczeniu dla kultury polskiej.

\section{Rola dziedzictwa kulturowego w budowaniu i umacnianiu tożsamości miejsca}

Jak wspomniano wcześniej, w Kazimierzu Dolnym rola dziedzictwa kulturowego w budowaniu i umacnianiu tożsamości miejsca była i jest ogromna. Bogata spuścizna kilku stuleci jest tym, co zbudowało stabilny grunt dla współczesności, dla rozwoju turystyki kulturowej w miejscowości. Drugim równie ważnym czynnikiem, który zdecydował o dzisiejszym obliczu Kazimierza Dolnego, było pojawienie się tu bohemy artystycznej i prawie już stuletnia ciągłość tradycji kolonii artystycznej (KAMIŃSKI 1983, ODOROWSKI 1991, DERECKI 1999), (fot. 3-5).

Kazimierz Dolny nie jest typowym miasteczkiem turystycznym. To, co wyróżnia go spośród innych tego typu ośrodków, to wyraźny stygmat elementów kultury i sztuki. Tworzy go:

- kilkadziesiąt galerii sztuki i rzemiosła artystycznego;

- cztery oddziały Muzeum Nadwiślańskiego (w tym jedyne w Polsce Muzeum Sztuki Złotniczej);

- Kazimierska Konfraternia Sztuki zrzeszająca ponad 50 członków;

- cztery festiwale artystyczne o wieloletniej tradycji (Festiwal Kapel i Śpiewaków Ludowych - 47 lat istnienia, festiwale filmowe od 1994 r., Festiwal Muzyki i Tradycji Klezmerskiej - siedem edycji) (fot. 6);

- festiwal muzyki organowej i kameralnej „Letnie Wieczory Muzyczne" (30 lat historii),

- wiele nowych cyklicznych inicjatyw kulturalnych (Festiwal Kazimierskie Inspiracje, Pardes Festiwal, Majowy Festiwal Muzyczny);

- cykl wydarzeń pod nazwą „Kazimierz bywa kobietą";

- warsztaty sztuki ludowej;

- Święto Wisły, Święto Jesieni; 
- Kanał Sztuki, czyli letnia wystawa plenerowa kilkudziesięciu twórców Kazimierskiej Konfraterni Sztuki i wiele innych.

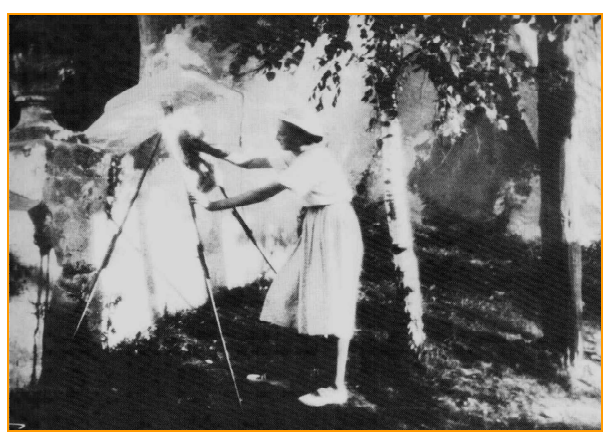

Fot. 3. Adeptka malarstwa w plenerze w Kazimierzu Dolnym (okres międzywojenny); autor: Edward Hartwig, ze zbiorów Muzeum Narodowego w Warszawie

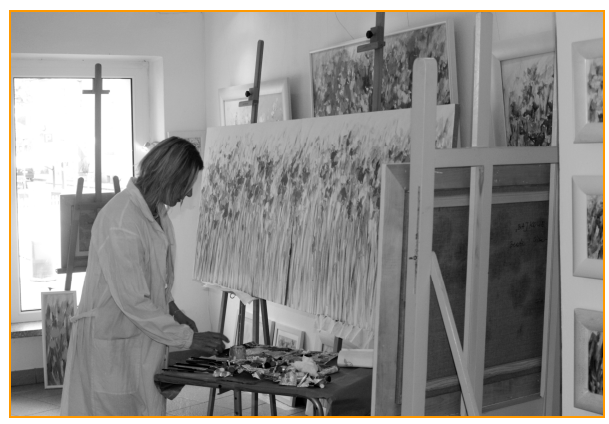

Fot. 5. Jedna z kazimierskich artystek w swojej pracowni Źródło: Urząd Miasta w Kazimierzu Dolnym

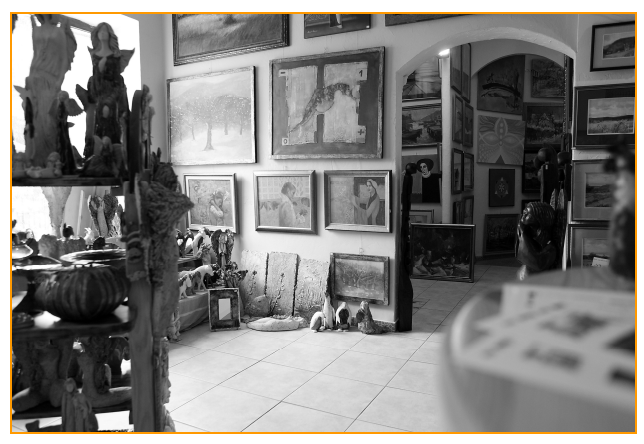

Fot. 4. Wnętrze jednej z kazimierskich galerii Źródło: Urząd Miasta w Kazimierzu Dolnym

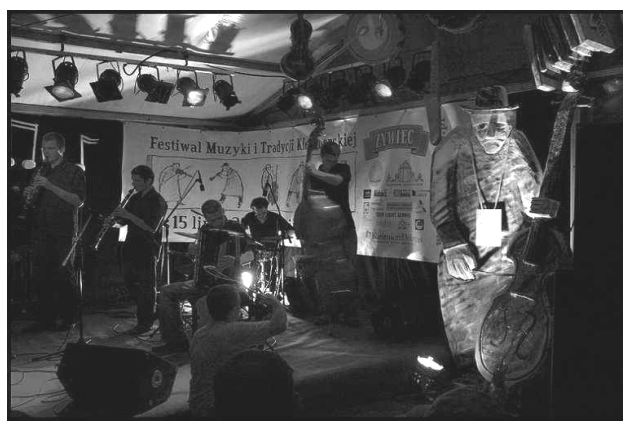

Fot. 6. Festiwal Muzyki i Tradycji Klezmerskiej Źródło: www.klezmerzy.pl

Nie sposób wymienić wszystkiego, co dzieje się każdego roku w miasteczku, ale także w najbliższej okolicy, bo coraz częściej ważne i bardzo wartościowe wydarzenia mają miejsce również poza ścisłym centrum miasteczka - w klubojadalni „Przystanek Korzeniowa”, w Galerii „Klimaty” w Męćmierzu, w "Zagrodowej Osadzie” w Uściążu (wymienione miejsca są oddalone o około dwa do pięciu kilometrów od centrum miasta).

Kazimierz Dolny liczy dziś niewiele ponad 2 tys. mieszkańców. Zamieszkiwany jest przez reżyserów, aktorów, dziennikarzy, kompozytorów, muzy- 
ków, malarzy, architektów, fotografów, złotników, poetów, kulturoznawców, historyków sztuki, przyrodników, entomologów, socjologów, filologów i..., długo by jeszcze wymieniać profesje tych, którzy tworzą ten barwny, jakże ciekawy konglomerat osób wrażliwych, czerpiących garściami z bogactwa Kazimierza, ale równie mocno odciskających na nim swój trwały ślad. Bez nich, ale także bez realizowanych tu wielu projektów kulturalnych, bez cotygodniowych spotkań, koncertów, wystaw, projekcji filmów miasteczko byłoby zupełnie inne. A w opinii ogółu uważane jest za mekkę artystów, miasto festiwali, miejsce rozkwitu sztuki (fot. 7-8).

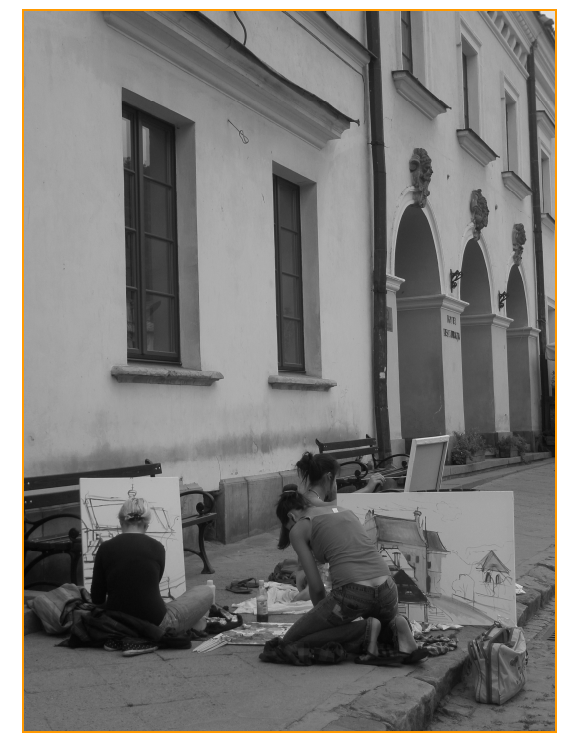

Fot. 7. Częsty widok w Kazimierzu - młodzi artyści malujący w plenerze

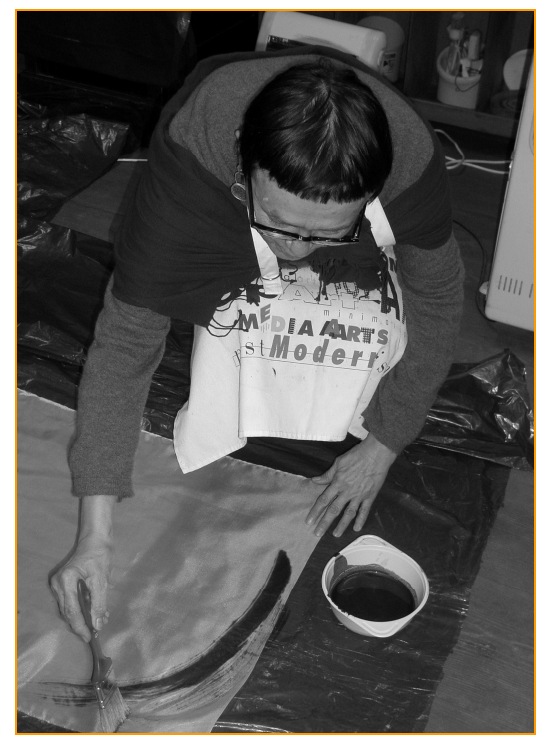

Fot. 8. Warsztaty malowania na jedwabiu

Źródło: Urząd Miasta w Kazimierzu Dolnym

\section{Turystyka w Kazimierzu Dolnym}

Jak wspomniano, pierwsze umocowane prawnie uznanie Kazimierza Dolnego za zabytek miało miejsce w 1947 r., jednak zainteresowanie miasteczkiem datuje się znacznie wcześniej, bo już od końca XVIII w. Początkowo 


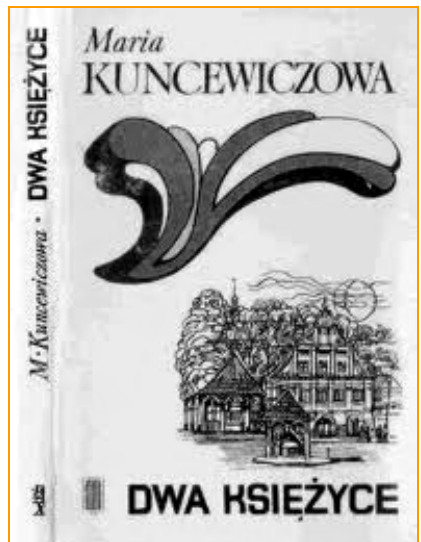

Rys. 2.

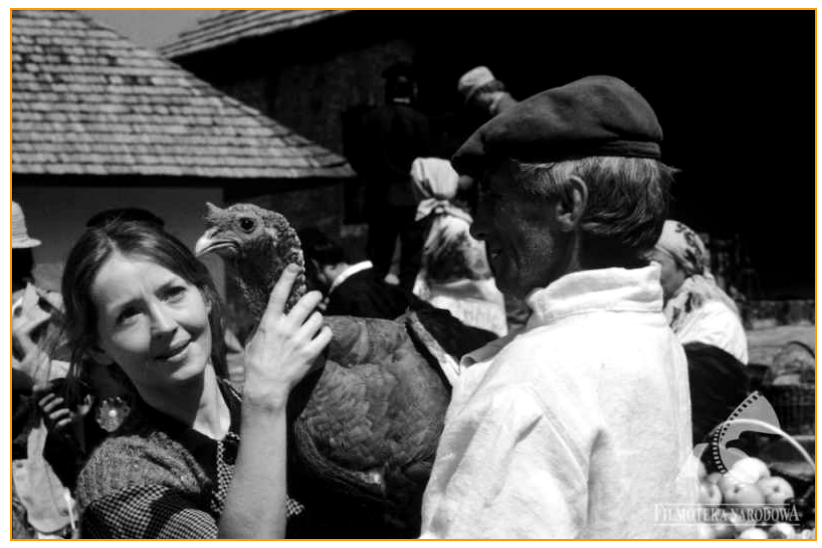

Fot. 9.
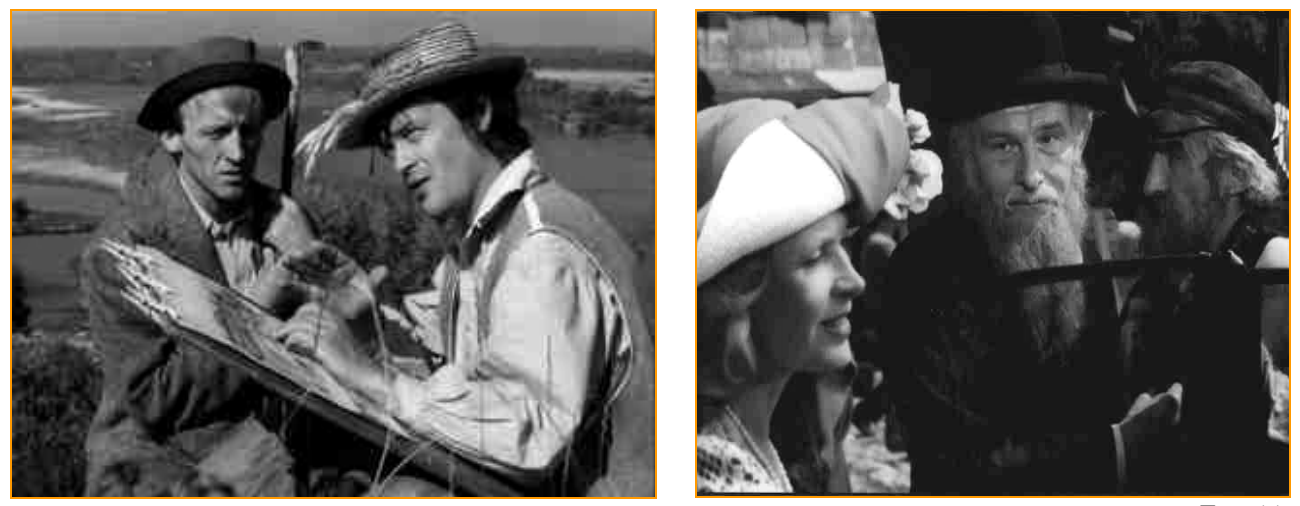

Fot. 10.

Fot. 11.

Rys. 2. Okładka książki M. KunCEWICZOWEJ (1980) Dwa księżyce.

Fot. 9-11. Sceny z filmu Dwa księżyce na podstawie zbioru opowiadań M. KUNCEWICZOWEJ (1980) pokazującego przedwojenny Kazimierz Dolny

Źródło: ogólnodostępne materiały publikowane w Internecie

były to tylko pojedyncze patriotyczne podróże, dokumentujące najcenniejsze pamiątki narodowe (m.in. królewskiego rysownika Zygmunta Vogla, Kazimierza Stronczyńskiego - autora Opisów i widoków zabytkówv w Królestwie Polskim). Stopniowo jednak charakter przyjazdów do Kazimierza się zmieniał i coraz częściej zaczęli odwiedzać nadwiślańskie miasteczko rysownicy, akwareliści, a od początku XX w. malarze, poeci i pisarze. Pierwszy w historii plener malarski zorganizował w Kazimierzu Dolnym w 1909 r. znany polski malarz, przyjaciel Paula Gauguina, Władysław Ślewiński. Po I wojnie światowej, od 1923 r. każde wakacje spędzali tu na plenerach uczniowie 
prof. Tadeusza Pruszkowskiego - malarze z Bractwa św. Łukasza i wielu innych (fot. 8). Artystowską (artystyczną) atmosferę i życie miasteczka przedwojennych lat nadzwyczaj celnie i ciekawie pokazała Maria Kuncewiczowa w Dwóch Księżycach zekranizowanych w 1993 r. przez Andrzeja Barańskiego (rys. 2, fot. 9-11).

Na mapie wielu miejsc odwiedzanych przez turystów Kazimierz Dolny wyróżniał się zdecydowanie. Nawet w okresie ponurego powojennego socrealizmu był inny - wolny, niezależny, bardziej autonomiczny. Miasto inspirowało i skłaniało do tworzenia. Dlatego w dojrzałych latach PRL powstało tu tak wiele ośrodków pracy twórczej, m.in. Dom Architektów, Dom Stowarzyszenia Dziennikarzy Polskich, ośrodek Ministerstwa Edukacji, Ministerstwa Sprawiedliwości, Politechniki Lubelskiej, UMCS i KUL, galerii sztuki i pracowni artystycznych, pracowano i wystawiano $\mathrm{w}$ plenerze, fotografowano i filmowano miasteczko wielokrotnie.

Równolegle $\mathrm{z}$ fascynacją Kazimierzem środowisk twórczych miasto wzbudzało zainteresowanie $\mathrm{u}$ osób mniej wyrobionych artystycznie, które wrażliwe były na piękno krajobrazu i architektury, przestrzeni niezmąconej urbanizacją, przemysłem i wielkomiejskością.

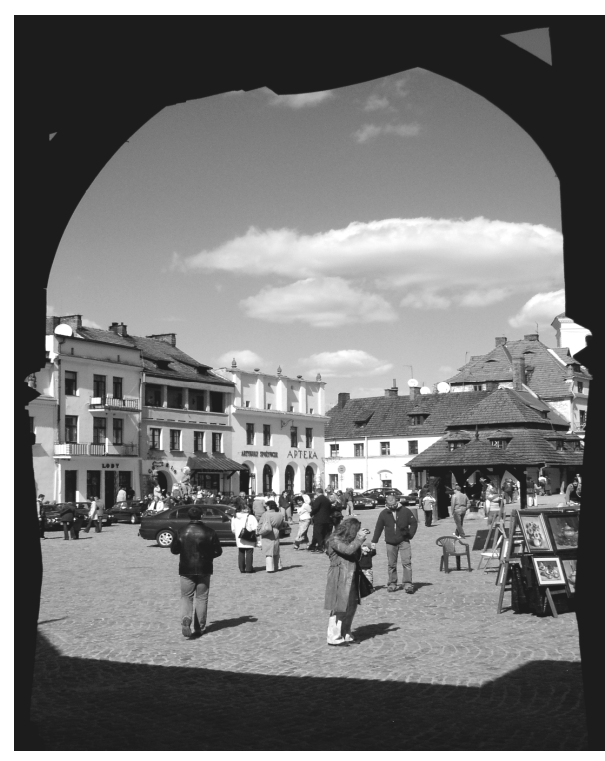

Fot. 12. Kazimierski rynek

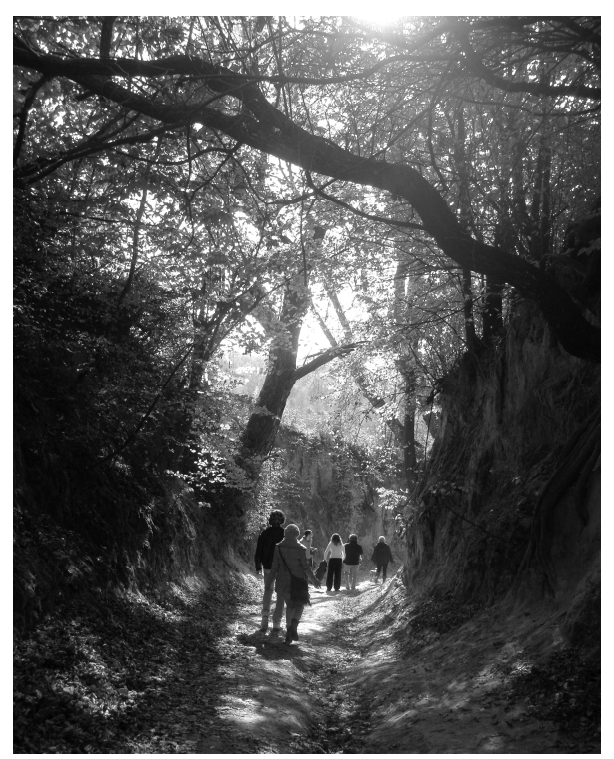

Fot. 13. Wąwóz Korzeniowy -popularne miejsce spacerów

Źródło: Urząd Miasta w Kazimierzu Dolnym 
Jednak $\mathrm{w}$ ostatnich dwóch dekadach nastąpiły wyraźne zmiany związane $\mathrm{z}$ żywiołowym rozwojem ruchu turystycznego. O ile $\mathrm{w}$ drugiej połowie XX w., aż do lat 90. turystyka w Kazimierzu Dolnym, podobnie zresztą jak w całym kraju, nadal miała charakter krajoznawczy, bardzo zindywidualizowany, wynikała z rzeczywistych pobudek poznawania miejsc, gdzie pobyty $\mathrm{w}$ miasteczku były dość długie, kiedy przyjeżdżano tu na letnisko z całą rodziną i „piernatami" - o tyle w ostatnich latach charakter pobytów turystycznych bardzo się zmienił (fot. 12-13).

Opracowując w 2011 r. Strategie marki Kazimierza Dolnego wywnioskowano, że obecnie miasto odwiedzają dwie kategorie turystów. Jedna, to zaciekawieni miastem, poszukujący, chcący odkrywać jego tajemnice, oraz druga, to ci, którzy z czysto snobistycznych pobudek „zaliczają” miasto, bo w Kazimierzu Dolnym trzeba być, bo jest on cool, bo byli tu już ich koledzy, posiedzieli na rynku, przeszli promenadą nad Wisłą, zrobili kilka obowiązkowych zdjęć, przywieźli tu swoje żony czy dziewczyny itd.

Trudno powiedzieć, która grupa jest liczniejsza. Czy i jakim zmianom będzie podlegać struktura ruchu turystycznego, jak ewoluować będą potrzeby turystów? Czy rozwiną się w kierunku jeszcze większego spłycenia oczekiwań, komercjalizacji, czy też pobyty będą rzadsze, a bardziej przemyślane, rzeczywiście pożądane i wynikające z fascynacji pięknem, wyjątkowością i niewątpliwą magią miasteczka. Na te pytania nie znamy jeszcze odpowiedzi. Wysiłki promocyjne samorządu idą w kierunku stawiania na jakość, a nie na liczbę turystów.

\section{Turystyka i kultura w Kazimierzu Dolnym - synergia czy konflikt?}

Kazimierz Dolny to niewątpliwie miejsce, gdzie turystyka spotyka kulturę. Już na początku rozważań zaryzykowano tezę, że w Kazimierzu Dolnym obie te dziedziny były i są, i prawdopodobnie będą nierozerwalnie połączone. Ale czy takie współwystępowanie nie jest pozbawione problemów?

We współczesnym świecie „życie” kultury nie jest proste, nigdy nie było, a dziś szczególnie, kiedy edukacja $\mathrm{w}$ tej dziedzinie ograniczana jest do minimum, gdy autentyzm przeżyć i doświadczeń artystycznych musi (sic!) być wykrzyczany i opowiedziany w sieci, gdy dawna wspólnota artystyczna, grupy twórcze, dawne kolonie artystyczne tracą swą siłę i są uboższe o ra- 
dość wspólnych spotkań, bo miejscem tych spotkań już dawno stał się Internet. Ile to razy można usłyszeć: jaka szkoda, że czasy się zmieniły, że ludzie tak rzadko spotykają się na balach artystów, które przed „erą www” były w miasteczku dość częste. Bale maskowe z loteriami, aukcjami dobroczynnymi, a nawet koncertami organizowano w Kazimierzu już w latach międzywojennych za czasów Bractwa św. Łukasza.

Czy turystyka w Kazimierzu Dolnym przeżywa obecnie swój najlepszy czas? Większość obserwatorów powiedziałaby, że tak, bo przecież miasteczko odwiedzane jest co roku przez kilkaset tysięcy turystów. Ale czy ten bardzo intensywny trend wychodzi miastu na dobre?
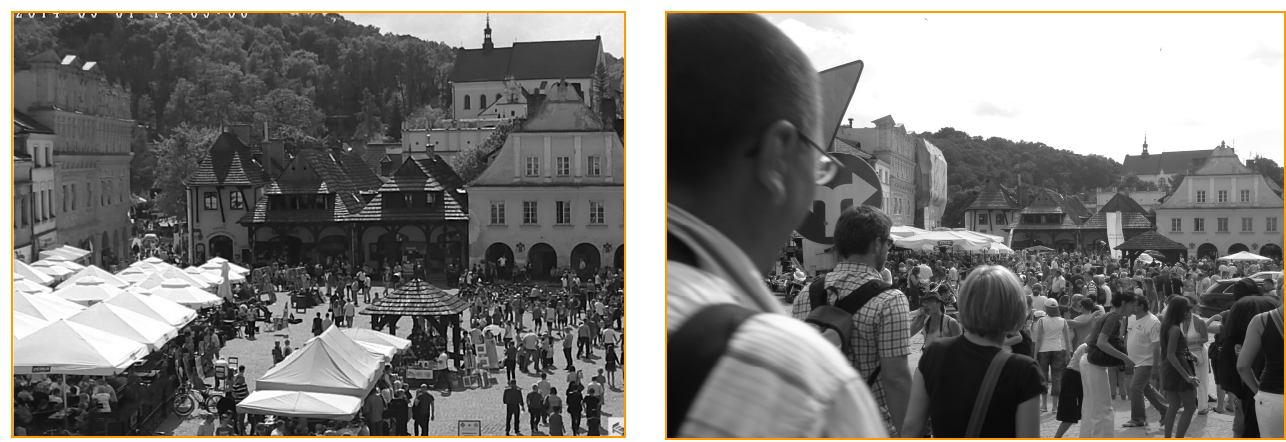

Fot. 14-15. Rynek w Kazimierzu w czasie długiego weekendu Źródło: Urząd Miasta w Kazimierzu Dolnym.

Obecnie turystyka w miasteczku stoi przed dylematem, czy zaspokajać gusta i potrzeby mniej wybrednej większości, czy walczyć o gości wymagających, poszukujących, spragnionych niecodziennych wrażeń.

Obserwując od kilkunastu lat sytuację turystyki w miasteczku, można dojść do wniosku, że w pewnym sensie należałoby porównać ją aktualnie do węża zjadającego swój własny ogon. Z jednej strony rzeczywiście został osiągnięty cel wielu interesariuszy ruchu turystycznego w miasteczku (hotelarzy, restauratorów, właścicieli galerii, sklepów z pamiątkami itd.). Dość wyraźnie w ciągu ostatniej dekady zwiększyła się liczba turystów przyjeżdżających do Kazimierza (i to nie tylko z Warszawy, jak sądzą niektórzy, ale z całej Polski, Europy, a nawet ze świata), wybudowano tu wiele wysokiej jakości obiektów turystycznych, z drugiej strony jednak, już nie tak często jak dawniej, widać w miasteczku znane twarze, ludzi kultury, sztuki i nauki przyjeżdżających na dłuższe pobyty. 
Masowość ruchu turystycznego to oczywiście nie jedyna przyczyna mniejszego zainteresowania Kazimierzem Dolnym ludzi kultury. Czy to powód do radości czy zmartwienia? Na pewno głębszej refleksji wymaga odpowiedź na pytania, jaką drogą powinno podążać miasto?, jaką wybrać strategię? i jakie podjąć kroki zmierzające do realizacji założonych celów? Podobną sytuację nie tak dawno przeżywał Kraków, który - podobnie jak Kazimierz Dolny - musiał odbyć lekcję pokory i dokonać przewartościowania błędnie zdefiniowanych celów. Dlatego strategia marki Kazimierza Dolnego opiera się na „idei wtajemniczenia”, czyli coraz głębszego wchodzenia w świat sztuki, bogatego dziedzictwa kulturowego, doświadczania „artystycznego" życia miasteczka.

Przeprowadzone przez P. WIECZOREK (2012) badania dowodzą, że nie zawsze dynamiczny rozwój ruchu turystycznego idzie w parze z zadowoleniem mieszkańców, a to co pożądane przez turystów i przedsiębiorców, nie zawsze jest akceptowane przez osoby niezwiązane $z$ turystyką a zamieszkujące miasteczko.

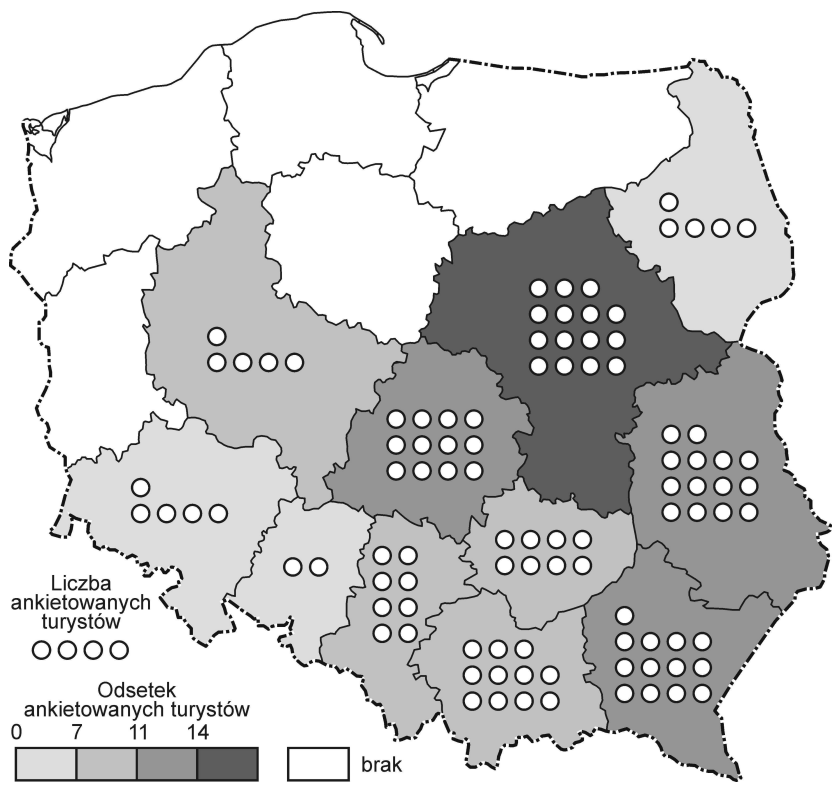

Rys. 3. Pochodzenie ankietowanych w Kazimierzu Dolnym w 2011 r. turystów Źródło: opracowanie autorów na podstawie P. WIECZOREK (2012)

W sierpniu 2011 r. na rynku kazimierskim przeprowadzono wywiad ze stu przypadkowo spotkanymi turystami. To fokusowe badanie potwierdziło 
ponadregionalny zasięg oddziaływania Kazimierza jako ośrodka turystycznego (rys. 3).

Zaskoczeniem nie był również fakt, że większość turystów deklarowała poznawczy $(54 \%)$ oraz wypoczynkowo-poznawczy $(29 \%)$ charakter pobytu (rys. 4). Jednak większość przyjezdnych deklarujących zwiedzanie, określało długość swojego pobytu jako jeden dzień albo kilka godzin, co dla gospodarki turystycznej miasta (szczególnie sektora hotelarskiego) nie jest korzystne.

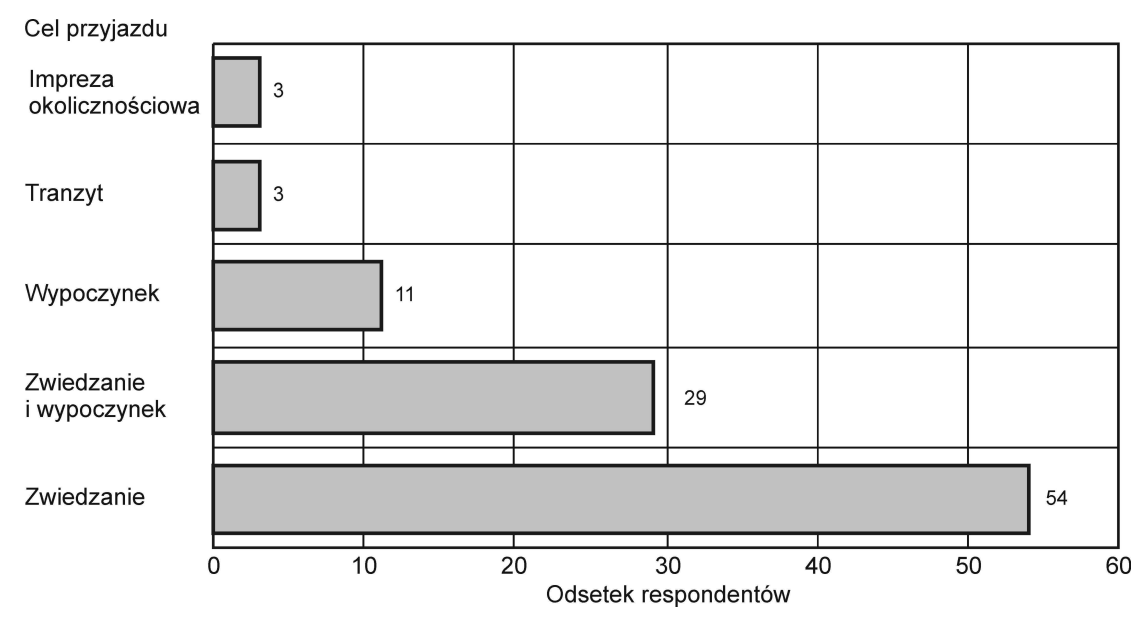

Rys. 4. Główny cel przyjazdu turystów do Kazimierza Dolnego w 2011 r.

Źródło: opracowanie autorów na podstawie P. WIECZOREK (2012)

Pewną powierzchowność odwiedzin, wynikającą prawdopodobnie m.in. z długości pobytu, potwierdzają obiekty/miejsca wskazywane przez turystów jako najbardziej atrakcyjne turystycznie. Ankietowanym turystom najbardziej podobał się kazimierski rynek oraz niepowtarzalna "atmosfera" miasteczka. Wśród wymienianych atrakcji znalazły się wszystkie ogólnie znane „sztandarowe” elementy, nie pojawiły się natomiast te, na których zwiedzenie należałoby poświęcić nieco więcej czasu (wąwozy lessowe, lapidarium na cmentarzu żydowskim itp.) (rys. 5).

W badaniach wzięli udział także mieszkańcy Kazimierza (sto osób), którzy mieli możliwość wypowiedzenia się na temat ruchu turystycznego w mieście oraz konsekwencji wynikających z jego dużego natężenia. Wśród najbardziej uciążliwych aspektów tego zjawiska osoby mieszkające w cent- 
rum miejscowości wymieniały najczęściej tłok, hałas, ale także wskazywały na turystów, którzy nieodpowiednio - ich zdaniem - zachowują się w miejscach publicznych. Do rzadziej wymienianych problemów zaliczyć można kłopoty związane ze zbyt dużym ruchem samochodów, czyli brak miejsc parkingowych w centrum oraz parkowanie samochodów na rynku wykorzystywanym głównie przez pieszych (rys. 6).

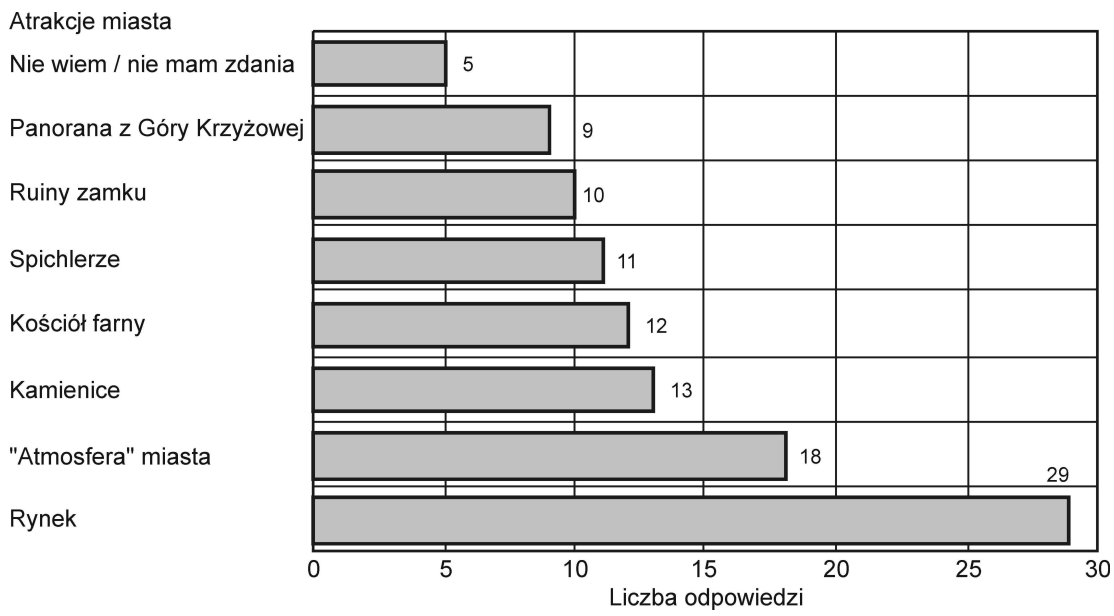

Rys. 5. Najatrakcyjniejsze elementy starego miasta w Kazimierzu w opinii turystów Źródło: opracowanie autorów na podstawie P. WIECZOREK (2012)

Elementy uciążliwe

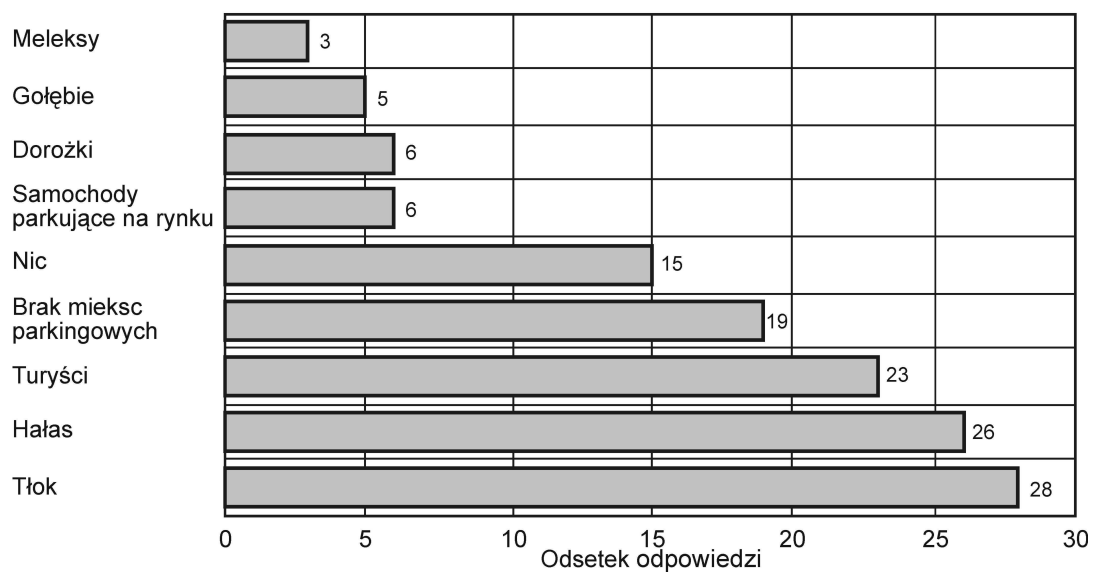

Rys. 6. Elementy najbardziej uciążliwe dla mieszkańców Kazimierza Dolnego Źródło: opracowanie autorów na podstawie P. WIECZOREK (2012) 
Wśród negatywów dużego ruchu turystycznego mieszkańcy wymieniali pogarszający się ogólny stan miasta, utrudnienia komunikacyjne oraz niedogodności związane $\mathrm{z}$ pobytem $\mathrm{w}$ tak niewielkiej przestrzeni jednocześnie zbyt dużej liczby osób, a także zmniejszające się bezpieczeństwo osób w niej przebywających (rys. 7).

Skutki
Poprawa infrastruktury
Kradzieże
Napaści
Zachowane dziedzictwo
Renowacja zabytków
Bijatyki
Praca dla mieszkańców
Nowe imwestycje
Hałas
Tłok
Wpływy do kasy miasta
Brak miejsc parkingowych
Zadbane miasto
Zaniedbane miasto

Skutki

Poprawa infrastruktury

Kradzieże

Napaści

Zachowane dziedzictwo

Renowacja zabytków

Praca dla mieszkańców

Nowe imwestycje

Hałas

Brak miejsc parkingowych

Zaniedbane miasto

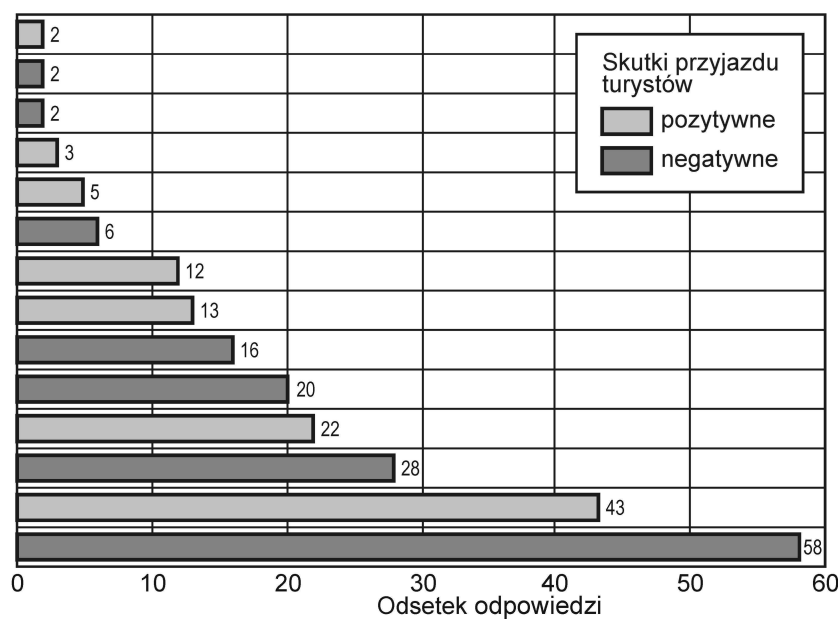

Rys. 7. Skutki przyjazdu turystów według ankietowanych mieszkańców Kazimierza Dolnego

Źródło: opracowanie autorów na podstawie P. WIECZOREK (2012)

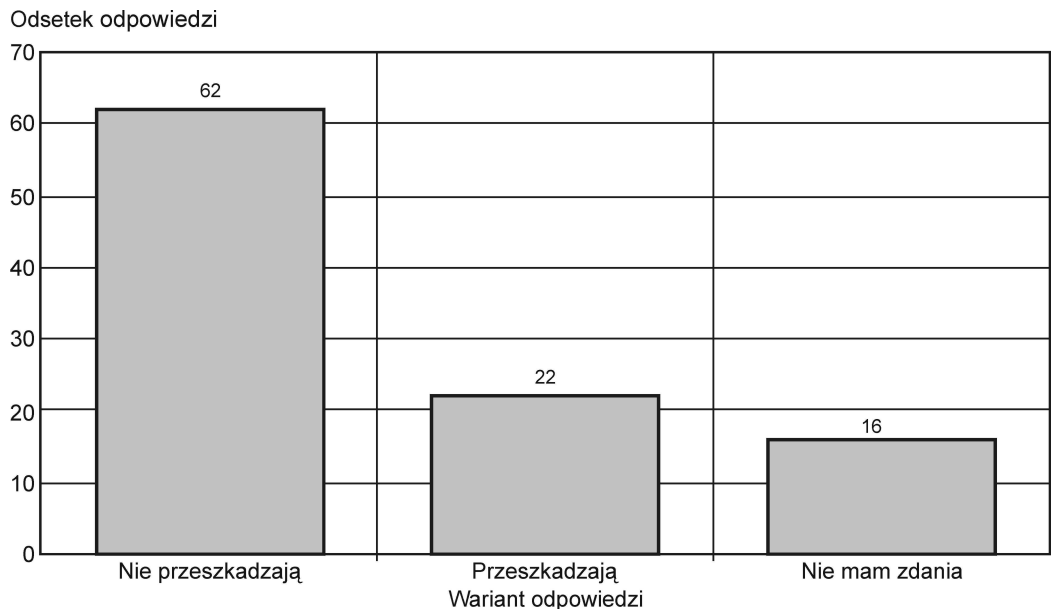

Rys. 8. Stosunek mieszkańców Kazimierza Dolnego do wydarzeń kulturalnych organizowanych w mieście

Źródło: opracowanie autorów na podstawie P. WIECZOREK (2012) 
Jednak według mieszkańców ruch turystyczny to nie tylko jego negatywne skutki, ale także różnego rodzaju korzyści, do których zaliczono m.in. większą troskę o wygląd miasta, wpływy finansowe do kasy miasta, nowe inwestycje i miejsca pracy. Zauważono także takie elementy, jak renowacja zabytków czy poprawa infrastruktury (rys. 7).

Jak już wspomniano wcześniej, Kazimierz Dolny to miejscowość, w której maja miejsce liczne wydarzenia kulturalne, przyciągające niekiedy tysiące uczestników. Większość ankietowanych mieszkańców miasta uważa, że nie są one uciążliwe i odbywają się zbyt rzadko, ale jednocześnie, ze względu na ich ogólną dostępność, przyczyniają się do tego, że w mieście żyje się lepiej i „,ciekawiej” (rys. 8-9).

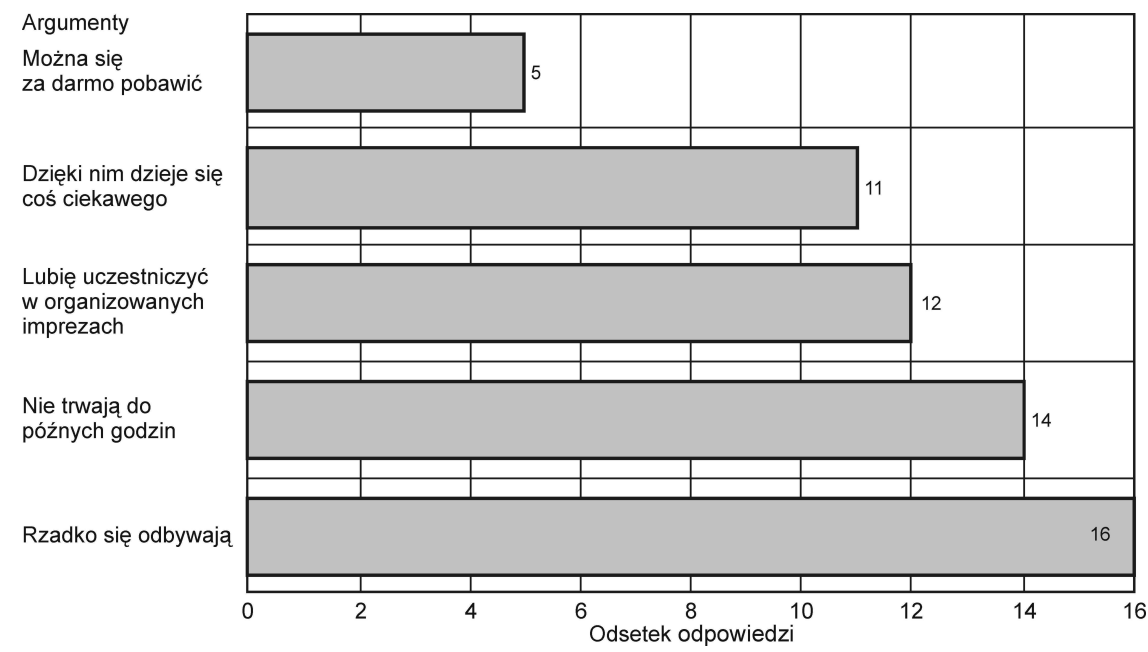

Rys. 9. Argumenty za organizacją wydarzeń kulturalnych na rynku w opinii mieszkańców Kazimierza Dolnego

Źródło: Opracowanie autorów na podstawie P. WIECZOREK (2012)

Warto przy tym zauważyć, że liczba opowiadających się za organizacją wydarzeń kulturalnych w mieście jest ponaddwukrotnie większa niż ich przeciwników (rys. 9-10).

Argumenty przeciwników organizacji wydarzeń kulturalnych powtarzają właściwie opinie charakterystyczne dla ogólnych uciążliwości związanych z przyjazdem tak dużej liczby turystów, do których oprócz tłoku i hałasu dodać jeszcze można zaśmiecanie miasta i widoczne nadużywanie napojów alkoholowych (rys. 10). 


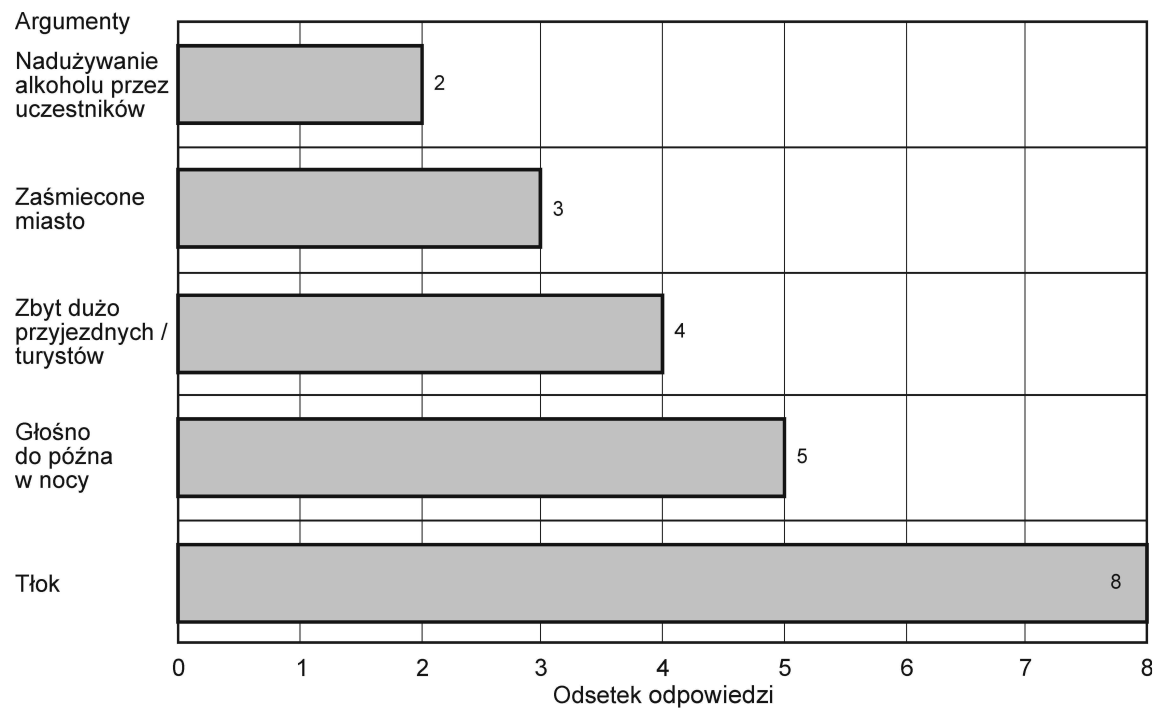

Rys. 10. Argumenty przeciwko organizacji wydarzeń kulturalnych na rynku w opinii mieszkańców Kazimierza Dolnego

Źródło: opracowanie autorów na podstawie P. WIECZOREK (2012)

Pytań i rozterek, jak zarządzać kulturą w miejscu tak „popularnym” jak Kazimierz Dolny, jest bardzo wiele. Na większość z nich nie znaleziono jeszcze prostej i jednoznacznej odpowiedzi. Na pewno jednak trzeba uświadomić sobie rzeczy rudymentarne, niezmienne, niezbędne do tego, by zachować ciągłość tradycji kulturalnej miejsca oraz jego niepowtarzalny charakter.

\section{Zamiast podsumowania}

W Kazimierzu Dolnym bez wątpienia odpowiedzialność za wyznaczanie właściwego kierunku działań w sferze kultury ponosi samorząd i jego instytucje kultury, w tym wypadku Kazimierski Ośrodek Kultury Promocji i Turystyki. Siedziba placówki (siedemnastowieczny szpital św. Ducha) została gruntownie wyremontowana, zyskując nowe możliwości lokalowe i użytkowe, i właśnie w najbliższym czasie czekają ją spore wyzwania. Dużą rolę w tworzeniu wartościowej oferty kulturalnej odgrywa również inna instytucja kultury, jaką jest Muzeum Nadwiślańskie, drugie co do wielkości muzeum w województwie lubelskim. 
Niebagatelne znaczenie ma tu również godna szacunku i uznania działalność kilku lokalnych organizacji pozarządowych, takich jak Stowarzyszenie „Dwa Brzegi” (organizator festiwalu Filmu i Sztuki Dwa Brzegi), Stowarzyszenie „Kazimierska Fara” (współorganizator wieloletniego cyklu koncertów organowych w kościele farnym), Towarzystwo Przyjaciół Miasta Kazimierza Dolnego (wydawca świetnego periodyku historyczno-kulturalnego pt. „Brulion Kazimierski” (fot. 15), organizator wielu wykładów monograficznych i spotkań przybliżających historię i genius loci miasteczka), stowarzyszenie Kazimierska Konfraternia Sztuki (organizujące wspólne wernisaże), Towarzystwo Opieki nad Zabytkami (wychodzące z inicjatywą społeczną zbiórki funduszy na restaurację i ratowanie najbardziej potrzebujących zabytków w Kazimierzu). Najbardziej pożądaną sytuacją byłaby pełna harmonii i otwartości współpraca pomiędzy wszystkimi wymienionymi podmiotami. Dotychczasowe doświadczenia pozwalają stwierdzić, że w tym przypadku jest nie najgorzej, czasem bardzo dobrze, a nawet wzorcowo.

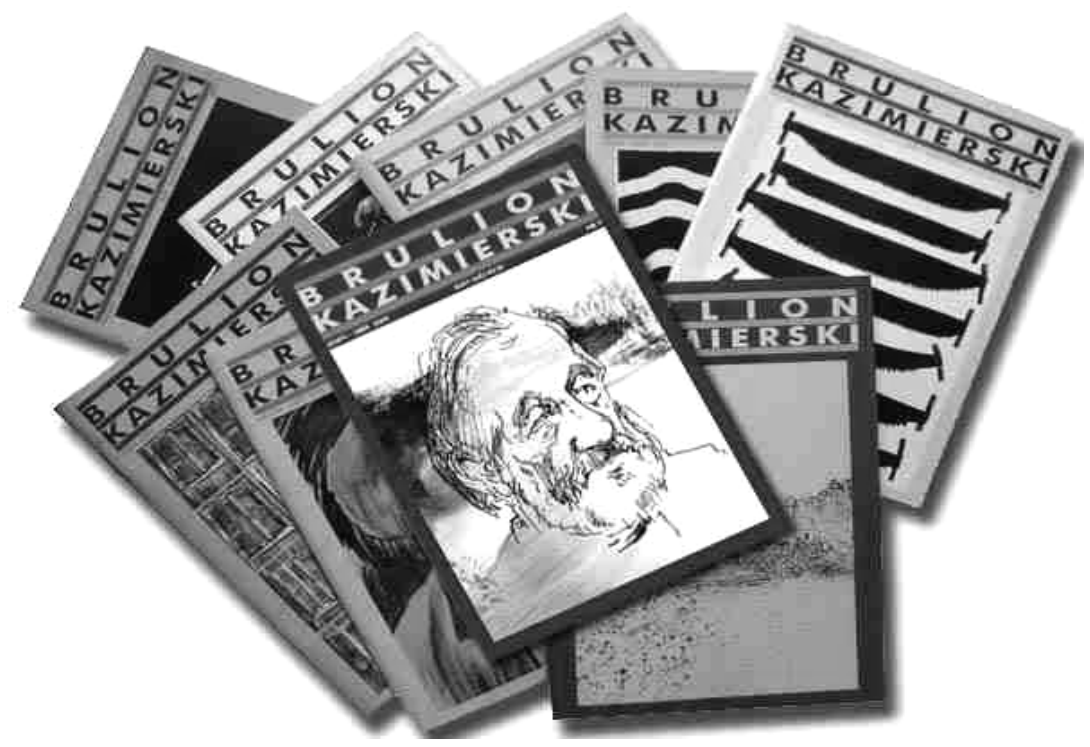

Fot. 15. Przykłady periodyku historyczno-kulturalnego „Brulion Kazimierski” Źródło: www.przyjacielekazimierza.pl

Kazimierz Dolny ma jeszcze to szczęście, że wiele osób prowadzących działalność gospodarczą, głównie w branży turystycznej, to ludzie o szerokich horyzontach, otwarci na sztukę, rozumiejący i czujący wyjątkowość 
miasteczka, wyzbyci kompleksów „prowincji”, biorący udział we wspólnych projektach, włączający się w dyskusje społeczne, gdy pojawiają się takie potrzeby, często inicjujący własne projekty artystyczne czy kulturalne. Oni także $\mathrm{w}$ niemałym stopniu są odpowiedzialni za zarządzanie marką miasta i budowanie pozytywnego wizerunku.

\section{BIBLIOGRAFIA}

„Brulion Kazimierski”, numery 1-8, Towarzystwo Przyjaciół Miasta Kazimierza Dolnego, Kazimierz Dolny.

DERECKI K., 1999, Mój Kazimierz, Lublin.

KOENNER M., 2008, Kazimierz Dolny, Natęczów, Puławy, Wyd. Buchman sp. z.o.o., Warszawa.

KAMIŃSKI I.J., 1983, Kazimierz nad Wista, Wydawnictwa Artystyczne i Filmowe, Warszawa, ss. 248.

KUNCEWICZOWA M., 1980, Dwa księżyce, Instytut Wydawniczy PAX, Warszawa, ss. 130.

METZER-SOBOTKOWSKA K., 2004, Kazimierz Dolny - przewodnik turystyczny, Prywatna Agencja Geograficzna, Warszawa.

NIEGODZISZ J.W., 2006, Kazimierz Dolny w 3 dni, Wyd. Sport i Turystyka, Warszawa.

ODOROWSKI W., 1991, Malarze Kazimierza nad Wista, Krajowa Agencja Wydawnicza, Warszawa, ss. 118.

WIECZOREK P., 2012, Społeczne i kulturowe dysfunkcje turystyki w historycznych centrach wybranych miast Polski. Przykład Krakowa, Sandomierza i Kazimierza Dolnego, praca magisterska napisana w Instytucie Geografii Miast i Turyzmu na Wydziale Nauk Geograficznych Uniwersytetu Łódzkiego, ss. 139.

\section{TOURISM AND CULTURE IN KAZIMIERZ DOLNY}

Key words: tourism, culture, cultural events, tourism and culture management

\section{Summary}

Kazimierz Dolny is currently the icon of polish culture and tourism. Crutial meaning in tourism development has the cultural heritage of the town - outstanding medieval and renaissance architecture, harmonious with Vistula landscape and its precious loess ravines.

With the population of about 2000, it is inhabited by many prominents: directors, actors, journalists, composers, musicians, painters, architects, photographers, goldsmiths, poets, culture and nature experts, art historians, entomologists, sociologists and other scholars, who create a specific conglomeration - they get the inspiration from the place, as well impress a stigma on it. Thanks to them, but also thanks to numerous cultural projects, meetings, concerts, exhibitions and festivals, Kazimierz Dolny is concidered to be a "mecca" for artists. This valuable cultural heritage was appreciated in 1994, while it entered the prestigious List of Historic Monuments in Poland.

The unique attractiveness of Kazimierz Dolny is a reason for considerably growing amount of tourists. The researches conducted in 2012 prove that dynamic tourism development is not always accompanied with inhabitants' sattisfaction - what is relevant for tourists and enterpreneurs is not always accepted by the inhabitants. 